\title{
Re-criticism of Geomantic Omen in Modern Design from the Perspective of Data Analysis
}

\author{
Qi Liu1,a, Huagang Yang², and Yiwei Zhang ${ }^{3}$ \\ ${ }^{1}$ Gold Mantis School of Architecture, Soochow University, No. 199 Ren Ai Road, Wu Zhong District, Jiangsu City, Suzhou Province, China \\ ${ }^{2}$ Kunming University of Science and Technology, No. 727 Jingming South Road, Chenggong District, Kunming, Yunnan \\ ${ }^{3}$ Ludong University, Room 232, No.49, Hongqi Mid-road 186, Zhifu District, Yantai, Shandong Province, China
}

\begin{abstract}
Geomantic omen is both strange and familiar to the contemporary people. It is not only a part of the traditional Chinese culture, but also contains the contradictions and disputes in Chinese long history of thought, practice and theory. This article is based on the context of modern design, discuss the reason of the Geomantic omen cannot be the key factors of modern design from three perspectives, including research trend, discipline development, practice creation. Through the summary of data, typical cases, and geomantic theory, it is believed that modern geomantic research should be based on rational evaluation and theoretical research. Except that, geomancy can be study not only by using modern science and technology, but also through transcending the ideological level. Finally, the idea of the future development of geomantic is set up for the re-thinking and re-exploration of the contemporary research.
\end{abstract}

\section{Trend analysis of overall research}

\subsection{Research trends in ancient times}

Wang Qiheng, a famous expert on architectural geomantic omen theory in China, pointed out the scientific nature of geomantic omen and the value of contemporary research in his book "Research on geomantic omen theory". On the other hand, he also pointed out that geomantic omen research cannot get rid of the shackles and fetters of superstition. This view is also based on the historical background of the controversy. ${ }^{[1]}$ Geomantic omen began to worship nature and spirit in the early period of human beings, and maintained consistency with the development of Chinese history. At the same time, geomantic omen embodied particularity. The whole development process of geomantic omen experienced a complex process from germination to maturity, from legend to life, from practice to theory, from fluctuation to stability and redifferentiation (Table 1).

Table 1. Setting Word's margins

\begin{tabular}{|c|c|c|c|}
\hline Period & Definition & Features & Theory \\
\hline $\begin{array}{c}\text { Primitive society } \\
\text { (budding period) }\end{array}$ & $\begin{array}{c}\text { Number and } \\
\text { sorcery }\end{array}$ & $\begin{array}{c}\text { From } \\
\text { primitive } \\
\text { worship to } \\
\text { fantasy. }\end{array}$ & $\begin{array}{c}\text { Observing } \\
\text { natural } \\
\text { celestial } \\
\text { phenomena }\end{array}$ \\
\hline $\begin{array}{c}\text { Shang and Zhou } \\
\text { Dynasties } \\
\text { (development } \\
\text { period) }\end{array}$ & $\begin{array}{c}\text { Choose } \\
\text { capital and } \\
\text { Divination }\end{array}$ & $\begin{array}{c}\text { For capital } \\
\text { building. }\end{array}$ & $\begin{array}{c}\text { event must be } \\
\text { divination } \\
\text { first. }\end{array}$ \\
\hline
\end{tabular}

\begin{tabular}{|c|c|c|c|}
\hline $\begin{array}{c}\text { Qin, Han, Wei, Jin, } \\
\text { southern and } \\
\text { Northern Dynasties } \\
\text { (maturity period) }\end{array}$ & $\begin{array}{c}\text { Tombs and } \\
\text { geomantic } \\
\text { omen }\end{array}$ & $\begin{array}{c}\text { Yin and } \\
\text { Yang five } \\
\text { lines } \\
\text { appears. }\end{array}$ & $\begin{array}{c}\text { Figure of the } \\
\text { house }\end{array}$ \\
\hline $\begin{array}{c}\text { Tang, song and } \\
\text { Yuan Dynasties } \\
\text { (prosper) }\end{array}$ & $\begin{array}{c}\text { Divination, } \\
\text { Fangjia and } \\
\text { geomantic } \\
\text { omen }\end{array}$ & $\begin{array}{c}\text { Gradually } \\
\text { combining } \\
\text { geomantic } \\
\text { omen with } \\
\text { religious } \\
\text { architecture }\end{array}$ & $\begin{array}{c}\text { The book of } \\
\text { Mansion }\end{array}$ \\
\hline $\begin{array}{c}\text { Ming and Qing } \\
\text { Dynasties } \\
\text { (declining period) }\end{array}$ & geomantic \\
omen & $\begin{array}{c}\text { The genre is } \\
\text { very } \\
\text { complex and } \\
\text { confusing. }\end{array}$ & $\begin{array}{c}\text { Ten books in } \\
\text { Yang Mansion }\end{array}$ \\
\hline $\begin{array}{c}\text { Contemporary } \\
\text { (New exploration } \\
\text { period) }\end{array}$ & geomantic \\
omen & $\begin{array}{c}\text { Gradually } \\
\text { nterdiscipli } \\
\text { nsychology } \\
\text { and other } \\
\text { subjects. }\end{array}$ & $\begin{array}{c}\text { Chinese } \\
\text { geomantic } \\
\text { omen }\end{array}$ \\
culture, etc. \\
\hline
\end{tabular}

The early geomantic omen is in the embryonic stage of development, and the initial intention comes from people's expectations for the improvement and beauty of life. In the Qin and Han Dynasties, with the unification of writing and currency, on the one hand, it promoted the scientific development of geomantic omen, on the other hand, it gradually breeds superstition. Historically, there has been a certain scale of criticism of geomantic omen since the Han Dynasty. In Lun Heng, Wang Chong, the representative of the Han Dynasty, criticizes the geomantic omen superstition of his time from the perspectives of residence, funeral system, life concept system and demonstration. ${ }^{[2]}$ Touched the essence of superstition in geomantic omen. 


\subsection{Contemporary research trends}

Nowadays, scholars such as Song Hong-xi have put forward the concept of contemporary natural geomancy while criticizing geomancy rationally. Objectively speaking, contemporary geomancy research has gradually abandoned the attitude of overpraise and overall criticism, showing a trend from perceptual judgment to rational research, and the exploration of this field has also been deepening. Starting from the theoretical research level, from the end of the Qing Dynasty to the present, the relevant theoretical books and documents are analysed by visual data (Table 2). It can be found that the contemporary development law of geomantic omen can be divided into three stages: before 2003, the development of geomantic omen tends to develop smoothly, while the development of geomantic omen in architecture or design is concerned. The domain has infiltrated, but there is no large-scale promotion and application. (Table 2)

Table 2. Visualized data analysis of geomantic omen Research

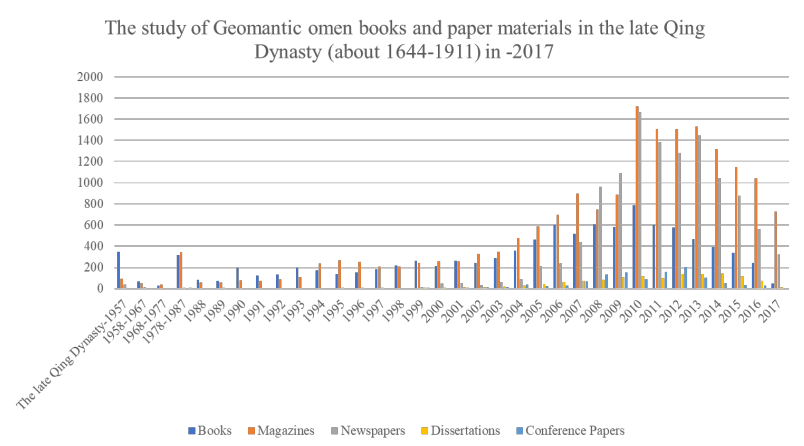

From 2003 to 2010, geomantic omen showed a rapid development trend, and the development of China's construction industry in this stage also showed a sustained growth trend, that is, in the context of the financial crisis in 2009, the national economy was in a downturn. During this period, the theory and viewpoints concerning the application of geomantic omen in the field of design were constantly enriched, and gradually began to dispel the single critical attitude towards geomantic omen in the past long period of time. Since 2010, the study of geomantic omen discipline has shown a trend of slow decline. The main reason is that discipline interdisciplinary and interdisciplinary research are constantly advancing in this period. This is the background of academic research in the process of blending and advancing natural science and geomantic omen, with the emergence of research platforms such as big data and Internet + . People have gradually changed their perspectives and methods of geomantic omen research, interpreting geomantic omen in a scientific, rational and logical way, discarding personal emotion and limitations, and conducting a rare but reasonable study. In today's unprecedented rapid development of science, geomantic omen discipline is still unable to get rid of the strange circle of superstition, there are also many phenomena that cannot be explained by science, which are closely related to people's activities and also incidental to contemporary social problems.

\subsection{Overall research characteristics}

First, the existing data show that there are a certain number of textual research books, literature, videos and network resources about geomantic omen theory and its application from the past to the present. However, from the overall content to the details of some principles, there is not a systematic combing, nor does it allow the public to form a common understanding. The same person in the same book has two meanings in the different Dynasty. ${ }^{[3]}$ It is not only the change of content, but also the great misunderstanding of the original meaning. There are many absurd and mythical meanings in the explanation of the application of some geomantic omen principles.

Secondly, there are ambiguous explanations for a phenomenon, such as the grave pattern of "Xinshan Bdirection and Xuchen". In Geomantic omen Seventysecond Bureau, it is considered that both the positive and the negative situation are evil, while in the Essentials of Three-dimensional Geography, it is considered that the bad luck should be combined with the water bureau. ${ }^{[4]}$ Even its source, such as Guo Pu's Funeral Books in the Wei and Jin Dynasties, which has been inherited from ancient times, is not from Guo $\mathrm{Pu}$ himself, but from the Tang and Song Dynasties, but the real author has no way to verify. Nevertheless, even today's scholars who study geomancy regard Guo $\mathrm{Pu}$ as the author of Funeral Books without any textual research. Before the Wei and Jin Dynasties, the founders of geomancy pedigrees such as Zhu Xian Tao and Qing Wuzi were not legendary figures in historical records. It is not difficult to imagine that geomantic omen has some inaccuracies in theory, so the accuracy in many oral and personal teachings is even more difficult to grasp.

Third, some of the principles of geomantic omen language are too obscure, resulting in incoherence of learning or use. For example, many sentences of the Ten Books of Yang Zhai are written in classical Chinese. Because each person's interpretation ability is different, and the literal meaning of ancient Chinese characters should be interpreted in accordance with the corresponding context. At the same time, textual research on ancient texts is also required to prove the corresponding geomantic omen theory, therefore, it still causes misunderstanding deviation in varying degrees. Of course, this also reflects the inadequacy of the study of ancient Chinese literature in contemporary education. Because of the difficulties in understanding and understanding the traditional geomantic omen theory, it is difficult for us to form a complete geomantic omen concept when we understand and learn geomantic omen knowledge, and at the same time, it is impossible to promote its application.

\section{Limitations of disciplinary development}

Contemporary geomancy research is not systematic and rigorous. Some scholars have proposed that geomantic omen is a scientific summary, which embodies the wisdom of ancient Chinese philosophy, science and 
aesthetics, and has its own logical relationship. It is a natural part of traditional architectural theory. However, from the perspective of the research system of this discipline, there are some shortcomings, or the current research is not perfect and mature enough. From the late Qing Dynasty to 2017, this research compared the research data of geomantic omen with other subjects (Table 3\& Table 4).

Table 3. Statistical tables for geomantic omen and other disciplines

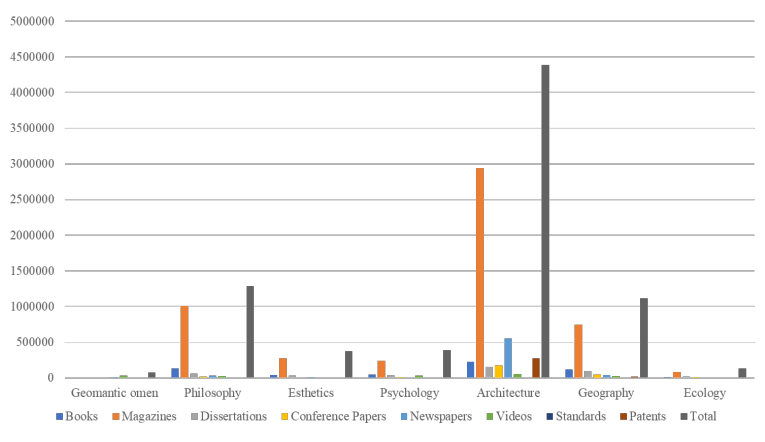

Table 4. Statistics of different types of subjects in the late Qing Dynasty (about 1644-1911) in -2017

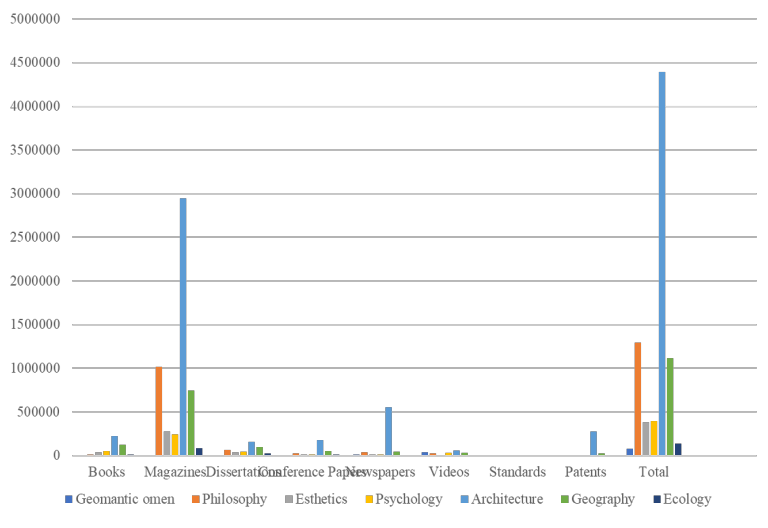

\section{1 limitations of academic research}

When geomantic omen compares with other disciplines or makes cross-disciplinary studies, the data are incomplete, and the interpretation of the past literature in modern and contemporary times is not deep enough. In addition, some geomantic practice experience and laws are difficult to verify accuracy through oral or personal teaching, literature and language, so that the perspective and knowledge obtained are one-sided. It is a meaningful, insightful and innovative research way to use the perspective of geomantic omen to interpret the discipline thoughts including philosophy and aesthetics. However, there are some limitations from the source of research subject resources, which are not accurate enough and easy to blur the concept.

\section{2 limitations of knowledge dissemination}

In the dissemination of subject knowledge, geomantic omen can be referred to by the public with little accurate information, which results in insufficient knowledge reserve at the understanding level. This is why in the long history of the past, the theory of geomantic omen has been either supportive or totally negative. Although people's attitude toward geomantic omen is more rational than in the past, the lack of basic data makes it difficult to break through the current situation. Therefore, the research of geomantic omen has been continuously supplementing, collecting, interpreting and analysing on the basis of predecessors. It still needs a process to transform obscure and difficult language into a mode of communication that can be universal to the public. From the point of view of data analysis, our existing research is also in the process.

\section{3 limitations of inheritance and innovation}

Based on the first two points, geomantic omen discipline needs to innovate and develop or has blind spots in combination with emerging science and technology, and it is also difficult to promote and intervene, whether in theory or in practice, which is also a dilemma that contemporary geomantic omen needs to break through. Chinese nature contains geomantic omen, emphasized in practice through technical means to target a realm of harmony is also present in architecture field. The living environment we are facing today has changed a lot. Besides environmental problems, social problems, ecological problems and resource problems, because of the richness of life dimension, we also need to face the addition and multiplication of all problems, which are far more complex than the problems that the geomantic omen view has to solve in the past. Although many of the natural concepts put forward by geomantic omen coincide with today's science, ideological exchanges are conducive to promoting exchanges and mutual promotion between the whole discipline and other disciplines. But it is not enough merely by thought. Ultimately, we must take the material environment of human settlement as the foothold. Therefore, at the level of practice and technology, geomantic omen still faces challenges.

\section{Hysteresis of creative practice}

\section{1 hysteresis of ideas}

Early Zhou Li • Xia Gong Sima Xia roughly described the principle and requirement that the method of selective settlement needs to observe the orientation and measure the land, which has preliminarily possessed scientific concepts and ideas. This reflects that the early concept of geomantic omen actually hoped to pass through practical experience and objective factual laws, but later development also separated the genre of metaphysics and superstition, which is an indisputable fact. Although today we should treat geomancy scientifically and rigorously and make use of geomancy, there are two important reasons why we still confine our creation to the circle. One is that we can't find a reasonable evaluation criterion to define geomantic omen; the other is that the rationality of geomantic omen used in modern design 
can't be judged in which aspects. Of course, we cannot say that these laws have no flexible scale, so as the basis for architectural creation is too rigid, but unreasonable content cannot be avoided or even boldly used through effective means, then it is not what we expect in the contemporary or future human settlements environment.

\section{2 hysteresis of objective practice}

Nowadays, we are familiar with many cases of geomantic omen in contemporary practice, such as the Bank of China Tower, Far East Finance Centre, Zhuge Bagua Village, etc. At the same time of these practical creations, theoretical advances are parallel. For example, Geomantic Omen in American Cities, written by Liang Xue, is a book that uses geomantic omen to analyse the planning and layout of American cities in a very detailed way. ${ }^{[5]}$ His research also reveals that foreign scholars' research on Chinese geomantic omen and even the collection and collation of ancient books have not only stayed in the cognitive stage. At the same time, with the progress of globalization in China, a large number of foreign scholars have gradually shifted their attention to the deep exploration of geomantic omen with the deepening of the study of Chinese culture. It is precisely because such a hot spot is before us that we should take this opportunity to discuss the realistic significance and historical value of geomantic omen in the contemporary era. If we cannot explain this problem and see its essence clearly, we cannot advance our understanding of geomantic omen only by full of passion. If we talk about removing the superstitious part of geomantic omen, it will be pale and powerless to carry forward its scientific part.

\section{3 hysteresis of technology}

On the one hand, the combination of geomantic omen and modern design technology is difficult in technical path, on the other hand, it lags behind the expression of modern science and technology geomantic omen in practice. Since the 21 st century, the field of architecture has realized the difficult establishment of non-linear models through BIM, Python, GIS and other software technologies, and even realized the transformation from virtual to reality through VR, AI and other emerging technologies, which is a very valuable breakthrough. Unfortunately, the combination of geomantic omen still stays in the collation and analysis of surface problems such as geomantic omen as a hot topic, whether geomantic omen has contemporary competitiveness or not, including this study can only be based on the modern literature and data of geomantic omen, for the combination, application and even promotion of geomantic omen in essence. The first phase is almost zero. In today's information explosion and ideological trend, it has also become a shackle for geomantic omen to break through at the ideological level.

\section{Conclusion}

At the present stage, based on the three levels of research trend, discipline development and creative practice, through certain data and combined with corresponding geomantic cases, it is considered that geomantic omen should not be considered as a key factor in modern design but reasonable ideas and concepts in geomantic omen can be used to assist contemporary design, and attention should be paid to geomantic omen. There are three possible directions for geomantic omen's future development. One is found that it does not exist and is gradually dying out, just as human beings have assumed the ether as a substance. Another is geomantic omen has become an important discipline with its scientific value constantly rooted and flourished. The third may discover its scientific value for a period of time and be constantly excavated, but after a time zero point, the subject is disconnected from the real world's life needs, gradually declining and becoming a clear stream in the long history. However, science is not the only standard by which we measure the world. There are emotions, spirits and hopes. The time has come and we need to make choices.

\section{References}

1. Wang Qiheng, Research of Geomantic Omen Theory (Tianjin University Press, 2005).

2. Department of history, Peking University, Annotation of Lun Heng (Zhong Hua Book Company, 1979).

3. Song Hongxi, A thorough criticism of Geomantic Omen and eight houses Fengshui, Real Estate Information of China, 18 (2016).

4. He Xiaoxi, Exploring the Source of Geomantic Omen (Southeast University press, 1990).

5. Liang Xue, Geomantic Omen in American Cities (Liaoning Science and Technology Press,2004).

6. Song Hongxi, Inheriting natural geomantic omen and building beautiful China, China-Today Forum, 17(2013). 